\title{
Extraction of minor actinides, lanthanides and other fission products by silica- immobilized BTBP/BTPhen ligands
}

Article

Accepted Version

Afsar, A., Distler, P., Harwood, L. M., John, J. and Westwood, J. (2017) Extraction of minor actinides, lanthanides and other fission products by silica-immobilized BTBP/BTPhen ligands. Chemical Communications, 53 (28). pp. 4010-4013. ISSN 1359-7345 doi: https://doi.org/10.1039/c7cc01286a Available at https://centaur.reading.ac.uk/69930/

It is advisable to refer to the publisher's version if you intend to cite from the work. See Guidance on citing.

To link to this article DOI: http://dx.doi.org/10.1039/c7cc01286a

Publisher: The Royal Society of Chemistry

All outputs in CentAUR are protected by Intellectual Property Rights law, including copyright law. Copyright and IPR is retained by the creators or other copyright holders. Terms and conditions for use of this material are defined in the End User Agreement.

www.reading.ac.uk/centaur 
Central Archive at the University of Reading

Reading's research outputs online 


\section{ChemComm}

\section{COMMUNICATION}

\section{Extraction of minor actinides, lanthanides and other fission products by silica-immobilized BTBP/BTPhen ligands $\dagger$}

Received 00th January 20XX, Accepted 00th January 20XX

DOI: $10.1039 / x 0 x \times 00000 x$

\author{
Ashfaq Afsar, ${ }^{\text {a Petr Distler, }}{ }^{\mathrm{b}}$ Laurence M. Harwood, ${ }^{\mathrm{a}} *$ Jan John ${ }^{\mathrm{b}}$ and James Westwood ${ }^{\mathrm{a}}$
}

www.rsc.org/

Novel BTBP [bis-(1,2,4-triazin-3-yl)-2,2'-bipyridine] / BTPhen [bis-(1,2,4-triazin-3-yl)-1,10-phenanthroline] functionalized silica gels have been developed to extract minor actinides, lanthanides and other fission products. BTPhen functionalized silica gel is capable of near-quantitative removal of $\mathrm{Am}$ (III) in the presence of $\mathrm{Eu}(\mathrm{III})$ from aqueous $\mathrm{HNO}_{3}$, while BTBP functionalized silica gel is able to remove problematic corrosion and fission products that are found in PUREX raffinates.

After the removal of uranium and plutonium in the PUREX (Plutonium and Uranium Redox EXtraction) process, post-PUREX raffinate still contains the lanthanides, other fission products and the minor actinides neptunium, americium and curium; the latter three elements being responsible for a large proportion of the long-term radiotoxicity and heat load of post-PUREX raffinate. ${ }^{1,2}$ One approach currently being studied for the long-term management of irradiated fuel is to separate these minor actinides from the lanthanides; after which they can be transmuted, using high-energy neutrons or fast neutrons in a Generation IV reactor, to short-lived radionuclides or stable non-radioactive elements. ${ }^{3-9}$ Separation of the minor actinides from the chemically similar lanthanides has been achieved by the SANEX solvent extraction process (Selective ActiNide EXtraction) using soft $\mathrm{N}$-donor ligands containing the 1,2,4-triazine moiety (Fig. 1). ${ }^{10-15}$ During this process, the radionuclides and non-radioactive fission products that are in an aqueous nitric acid phase are treated with the extraction reagent dissolved in an organic phase. CyMe4BTBP 2 is the current European reference ligand capable of performing the selective extraction of minor actinides directly from nitric acid solutions into an organic solvent and a laboratory demonstration has been successfully carried out on post-PUREX raffinate. ${ }^{16}$ However, 6,6'-bis(5,5,8,8-tetramethyl-5,6,7,8tetrahydrobenzo[e][1,2,4]triazin-3-yl)-2,2'-bipyridine $\quad\left(\mathrm{CyMe}_{4}-\right.$ BTBP) 2 not only selectively separates the minor actinides from the lanthanides, but it also co-extracts certain corrosion and fission

\footnotetext{
a. School of Chemistry, University of Reading, Whiteknights, Reading, Berkshire RG6 6AD, UK. E-mail: l.m.harwood@ reading.ac.uk

b. Department of Nuclear Chemistry, Czech Technical University in Prague, Břehova 7, 11519 Prague 1, Czech Republic.E-mail: jan.john@fjfi.cvut.cz

$\dagger$ Electronic Supplementary Information (ESI) available: [details of any supplementary information available should be included here]. See
} DOI: $10.1039 / \mathrm{x} 0 \mathrm{xx} 00000 \mathrm{x}$ products such as $\mathrm{Ni}(\mathrm{II}), \mathrm{Pd}(\mathrm{II}), \mathrm{Ag}(\mathrm{I})$ and $\mathrm{Cd}(\mathrm{II})$, complicating the separation of trivalent actinides for transmutation. ${ }^{17}$

Although much progress has been made concerning the development of extractants for the liquid-liquid extraction processes that can partition minor actinides from lanthanides, far less effort has been placed on a solid-liquid extraction and separation of the minor actinides from the corrosion and fission products.

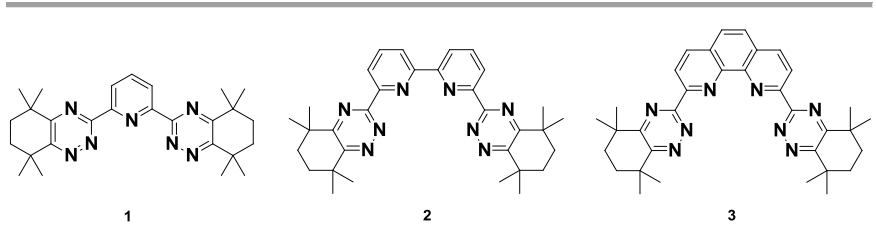

Fig. 1 Structural formulae of $\mathrm{CyMe}_{4}-\mathrm{BTP} \mathbf{1}, \mathrm{CyMe}_{4}-\mathrm{BTBP} 2$ and $\mathrm{CyMe}_{4}$ BTPhen 3

Considering that the minor actinide content in post-PUREX raffinate is smaller than that of $\mathrm{U}$ and $\mathrm{Pu}$ in the spent fuel, immobilization of actinide-selective ligands onto solid supports could provide an alternative method for carrying out separation and preconcentration of minor actinides from PUREX raffinates. ${ }^{18-20}$ Further benefits of a system based on a solid phase extractant include no requirement for mixing or phase separation, and possible use of pressure or vacuum to increase flow rate, or use of magnetic separation. ${ }^{19,21,22}$ We have recently demonstrated that, when magnetic nanoparticles (MNPs) are combined with ligands such as 2,9bis(5,5,8,8-tetramethyl-5,6,7,8-tetrahydrobenzo[e][1,2,4]triazin-3yl)-1,10-phenanthroline (CyMe4-BTPhen) 3, these functionalized MNPs can be used either to extract both minor actinides and lanthanides at low concentrations of $\mathrm{HNO}_{3}$ or to extract minor actinides selectively over lanthanides at high $(4 \mathrm{M})$ concentration of $\mathrm{HNO}_{3}$. These functionalized MNPs can be collected magnetically in preference to centrifugation. ${ }^{23}$ In this work, we report an alternative technology for the sequential separation of fission products and then minor actinides from lanthanides using a two-column system, the first packed with BTBP-functionalized $\mathrm{SiO}_{2}$ gel and the second with BTPhen-functionalized $\mathrm{SiO}_{2}$ gel.

The ligand 6,6'-bis(5,6-bis(bromomethyl)-1,2,4-triazin-3-yl)-2,2'bipyridine (tetra-bromomethyl-BTBP) 6 was synthesized by our previously reported protocol $(\mathrm{ESI} \dagger){ }^{24,25}$ As a solid support for the BTBP 6, aminopropyl-functionalized $\mathrm{SiO}_{2}$ gel 7 was purchased from 
Sigma Aldrich. This BTBP ligand 6 was then directly immobilized onto the $\mathrm{SiO}_{2}$-gel (Scheme 1). The tetra(4-hydroxyphenyl)BTPhen 11 was synthesized by the condensation reaction of bis(diaminodihydrazide) $\mathbf{9}$ with 4,4'-dihydroxybenzil $\mathbf{1 0}$ as shown in Scheme 2.,26-28 This tetra(4-hydroxyphenyl)-BTPhen ligand $\mathbf{1 1}$ was then immobilized onto commercially available chloropropylfunctionalized $\mathrm{SiO}_{2}$ gel 12 (Scheme 3).

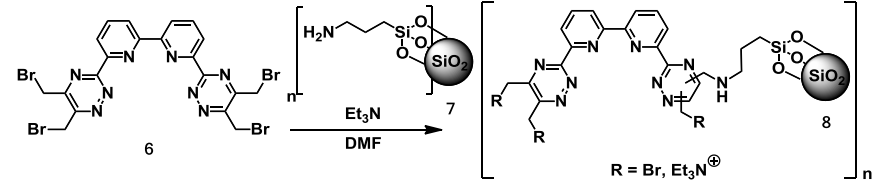

Scheme 1 Immobilization of BTBP 6 on silica gel.

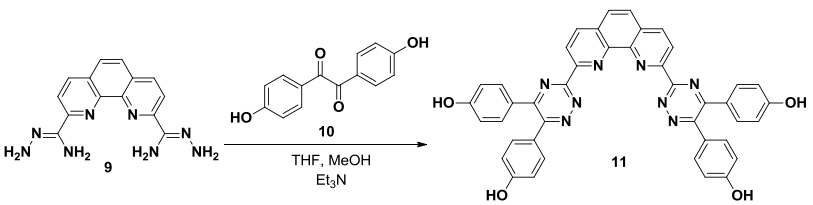

Scheme 2 Synthesis of tetra(4-hydroxyphenyl)BTPhen 11.

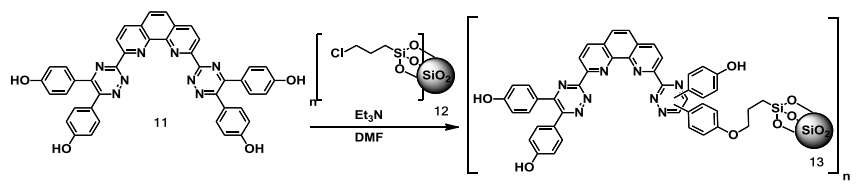

Scheme 3 Immobilization of BTPhen 11 on silica gel.

Several characterization methods were employed to assess the degree of immobilization of BTBP $\mathbf{6}$ and BTPhen 11 ligands onto the silica surface. The presence of bands at $1500-1600 \mathrm{~cm}^{-1}$ owing to $\mathrm{C}=\mathrm{C}$ aromatic vibrations were observed in the FT-IR spectra (ESI $\dagger$ ) for the BTBP-functionalized $\mathrm{SiO}_{2}$ gel 8 and BTPhen-functionalized $\mathrm{SiO}_{2}$ gel 13. Elemental analysis (ESI $\dagger$ ) showing an increase in the content of $\mathrm{C}, \mathrm{H}$ and $\mathrm{N}$ of the functionalized silica and thermogravimetric analysis (ESI + ) allowed the determination of the nature and degree of surface modification in each case indicating that the amount of BTBP ligand 6 bound onto the $\mathrm{SiO}_{2}$ surface was about $c a$. $14 \%$; while the content of BTPhen ligand $\mathbf{1 1}$ in the BTPhen-functionalized $\mathrm{SiO}_{2}$ gel $\mathbf{1 3}$ was estimated to be $c a$. $10 \%$ (ESI $\dagger$ ).

The aqueous solutions for the solid phase extraction experiments were prepared by spiking nitric acid solutions $(0.001-4 \mathrm{M})$ with stock solutions of ${ }^{241} \mathrm{Am}$ and ${ }^{152} \mathrm{Eu}$ and then adding $1 \mathrm{~mL}$ of spiked aqueous solution to $14 \mathrm{mg}$ of BTBP-functionalized $\mathrm{SiO}_{2}$ gel 8 or 17 $\mathrm{mg}$ of BTPhen-functionalized $\mathrm{SiO}_{2}$ gel 13. The suspension was sonicated for $10 \mathrm{~min}$ and shaken at $1800 \mathrm{rpm}$ for $90 \mathrm{~min}$. After centrifuging for $10 \mathrm{~min}$, aliquots of the supernatant were separated and taken for gamma measurements. The weight distribution ratios is defined as $D_{\mathrm{w}}=\left(A_{0}-A\right) / A$. V/m, where $A_{0}$ and $A$ were initial and final number of counts in the taken standard/aliquot, $V$ is a volume of an aqueous phase shaken and $m$ is a mass of the material $\mathbf{8}$ or 13. The separation factor is $\mathrm{SF}_{\mathrm{Am} / \mathrm{Eu}}=D_{\mathrm{wAm}} / D_{\mathrm{wEu}}$.

Fig. 2 shows the weight distribution ratios for Am(III) and Eu(III) ( $D_{\mathrm{wAm}}$ and $D_{\mathrm{wEu}}$ ) and the separation factors for Am(III) over Eu(III) $\left(\mathrm{SF}_{\mathrm{Am} / \mathrm{Eu}}\right)$ for BTBP-functionalized $\mathrm{SiO}_{2}$ gel $\mathbf{8}$ as a function of nitric acid concentration $(0.001 \mathrm{M}-4 \mathrm{M})$. The separation factors were calculated as $\mathrm{SF}_{\mathrm{Am} / \mathrm{Eu}}=32 \pm 17,193 \pm 171,46 \pm 45$ and $8 \pm 7$ at 0.001 ,
$0.1,1$ and $4 \mathrm{M} \mathrm{HNO}_{3}$, respectively. The low separation factor values indicate that BTBP ligand 6 immobilised on $\mathrm{SiO}_{2}$ gel did not significantly differentiate in the extraction of $\mathrm{Am}$ (III) or $\mathrm{Eu}(\mathrm{III})$ from $\mathrm{HNO}_{3}$ solutions. On the other hand, for BTPhen-functionalized $\mathrm{SiO}_{2}$ gel 13, high weight distribution ratios $\left(D_{\mathrm{w}}>90\right)$ were obtained for both $\mathrm{Am}(\mathrm{III})$ and $\mathrm{Eu}(\mathrm{III})$ at $0.001 \mathrm{M} \mathrm{HNO}_{3}$ solution with no selectivity $\left(\mathrm{SF}_{\mathrm{Am} / \mathrm{Eu}}=0.69 \pm 0.04\right)$ for $\mathrm{Am}(\mathrm{III})$ over $\mathrm{Eu}(\mathrm{III})$. At $0.1 \mathrm{M} \mathrm{HNO}_{3}$, a more significant increase in $D_{w}$ values was observed for Am(III) $\left(D_{w \mathrm{Am}}=4883 \pm 974\right)$ than for $\mathrm{Eu}(\mathrm{III})\left(D_{w \mathrm{Eu}}=630 \pm 51\right)$ resulting in $\mathrm{SF}_{\mathrm{Am} / \mathrm{Eu}}=7.7 \pm 1.7$. With increasing $\mathrm{HNO}_{3}$ concentration $(1 \mathrm{M})$, decreases in the $D_{w}$ values for both $\mathrm{Am}$ (III) and Eu(III) were observed $\left(D_{w \mathrm{Am}}=250 \pm 12, D_{w \mathrm{Eu}}=4.2 \pm 0.4\right)$, but a higher separation factor $\left(\mathrm{SF}_{\mathrm{Am} / \mathrm{Eu}}=60 \pm 6\right)$ resulted. Interestingly, at $4 \mathrm{M} \mathrm{HNO}_{3}$ a further decrease in $D_{w}$ value for Am (III) gave $D_{w \mathrm{Am}}=28 \pm 1$ but, in this case the $D_{w}$ value observed for $\mathrm{Eu}(\mathrm{III})$ of $D_{w \mathrm{Eu}} \approx 0.2$ and the resulting separation factor $\left(\mathrm{SF}_{\mathrm{Am} / \mathrm{Eu}} \approx 140\right)$, meant that only $\mathrm{Am}(\mathrm{III})$ was retained on the BTPhen-functionalized $\mathrm{SiO}_{2}$ gel 13. This effect of $\mathrm{HNO}_{3}$ concentration on the degree of extraction of Am(III) and $\mathrm{Eu}$ (III) mirrors that of $\mathrm{CyMe}_{4}-\mathrm{BTPhen}$ functionalized MNPs where we proposed that the shortness of the linking-chain on the MNPs constrains the $\mathrm{CyMe}_{4}-\mathrm{BTPhen}$ ligand to form 1:1 complexes with $\mathrm{M}(\mathrm{III})$ cations with 3 nitrates ligating for the 10-coordination and so making the complex electronically neutral. ${ }^{23,29}$ Extraction capabilities of aminopropyl-functionalized $\mathrm{SiO}_{2}$ gel 7 and chloropropylfunctionalized $\mathrm{SiO}_{2}$ gel 12 were also investigated; however no extraction was observed for $\mathrm{Am}(\mathrm{III})$ or $\mathrm{Eu}(\mathrm{III})$, over the full range of concentrations of $\mathrm{HNO}_{3}$.

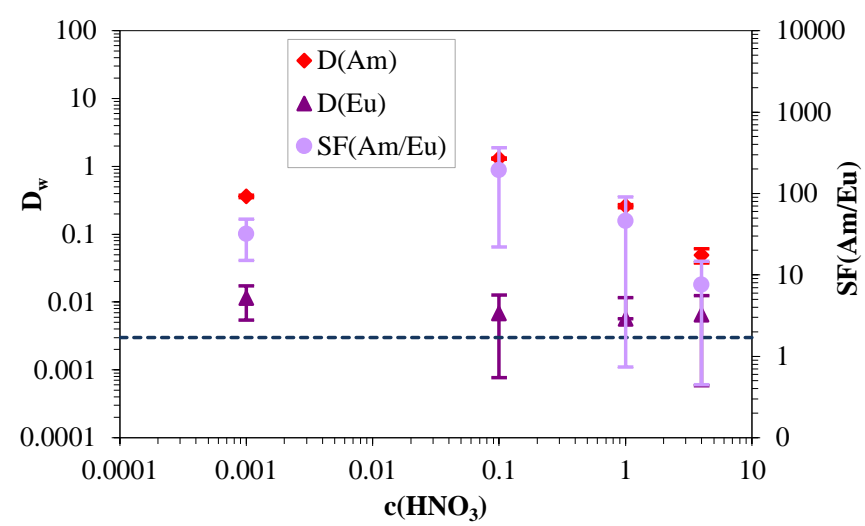

Fig. 2 Extraction of $\mathrm{Am}(\mathrm{III})$ and $\mathrm{Eu}(\mathrm{III})$ by BTBP-functionalized $\mathrm{SiO}_{2}$ gel 8 as a function of nitric acid concentration.

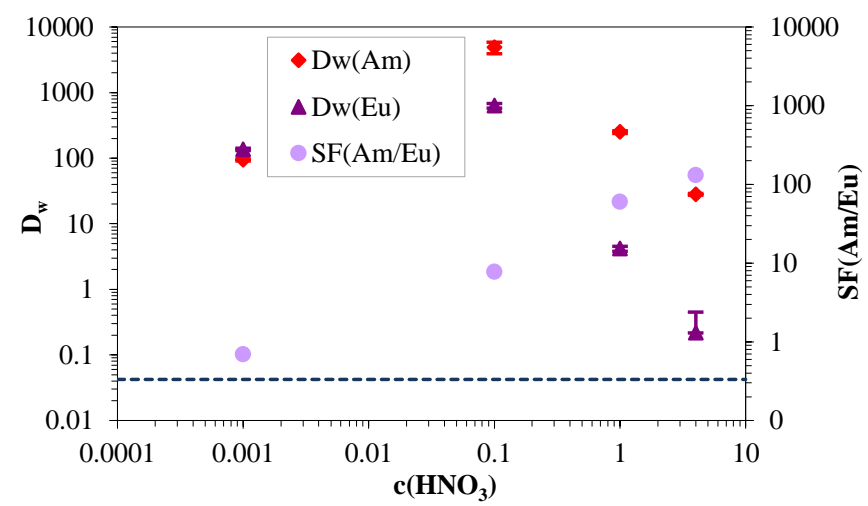

Fig. 3 Extraction of $\mathrm{Am}(\mathrm{III})$ and $\mathrm{Eu}(\mathrm{III})$ by BTPhen-functionalized $\mathrm{SiO}_{2}$ ge 13 as a function of nitric acid concentration.

To investigate whether the BTBP-functionalized $\mathrm{SiO}_{2}$ gel 8 had any potential applications in the removal of fission and corrosion 
products such as $\mathrm{Ni}(\mathrm{II}), \mathrm{Pd}(\mathrm{II}), \mathrm{Ag}(\mathrm{I})$ and $\mathrm{Cd}(\mathrm{II})$, extraction experiments were performed to extract metal ions from $2 \% \mathrm{HNO}_{3}$ solution $(\mathrm{pH}=0.5)$ using a column technique. Functionalized $\mathrm{SiO}_{2}$ gel $8(10 \mathrm{~g}, \sim 1.4 \mathrm{~g}$ BTBP 6 loading) packed into a glass column (diameter $3.8 \mathrm{~cm}$, bed volume $\sim 35 \mathrm{~mL}$ ) was washed with $2 \% \mathrm{HNO}_{3}$ solution $(100 \mathrm{~mL})$. Standard solutions at $\mathrm{pH} 0.5$ containing a range of metals each at $100 \mathrm{ppb}$ concentration $(100 \mathrm{~mL})$ were then passed through the column at a rate of $10 \mathrm{~mL}$ per minute. The filtrate was collected and analysed by ICP-MS. The uptake of various metal ions - Sc(III), $\mathrm{Mn}(\mathrm{II}), \mathrm{Fe}(\mathrm{III}), \mathrm{Co}(\mathrm{II}), \mathrm{Ni}(\mathrm{II}), \mathrm{Cu}(\mathrm{II}), \mathrm{Zn}(\mathrm{II}), \mathrm{Mo}(\mathrm{IV}), \mathrm{Ag}(\mathrm{I}), \mathrm{Cd}(\mathrm{II})$, $\mathrm{Sb}(\mathrm{V}), \mathrm{Pb}$ (II), $\mathrm{Pd}(\mathrm{II}), \mathrm{Os}(\mathrm{IV}), \mathrm{Ir}(\mathrm{III}), \mathrm{Pt}(\mathrm{IV}), \mathrm{Au}(\mathrm{III}), \mathrm{Zr}(\mathrm{IV}), \mathrm{Nb}(\mathrm{V})$, $\mathrm{Hf}(\mathrm{IV}), \mathrm{Ta}(\mathrm{V}), \mathrm{W}(\mathrm{VI})$ and $\mathrm{Re}(\mathrm{IV})$ at $\mathrm{pH} 0.5$, by BTBP-functionalized $\mathrm{SiO}_{2}$ gel $\mathbf{8}$ shows $>80 \%$ of uptake efficiency for all the metals except $\mathrm{Sb}(\mathrm{V})$ in Fig. 4. Importantly near quantitative extraction of certain problematic corrosion and fission products [Ni(II), $\mathrm{Pd}(\mathrm{II}), \mathrm{Ag}(\mathrm{I})$ and $\mathrm{Cd}(\mathrm{II})]$ that are found in the nitric solutions of PUREX raffinates was observed. Significantly, the BTBP-functionalized $\mathrm{SiO}_{2}$ gel $\mathbf{8}$ did not show any affinity towards alkali metals or alkaline earth metals such as $\mathrm{Na}^{+}, \mathrm{K}^{+}, \mathrm{Mg}^{2+}$ and $\mathrm{Ca}^{2+}$ or $\mathrm{Al}^{3+}$.

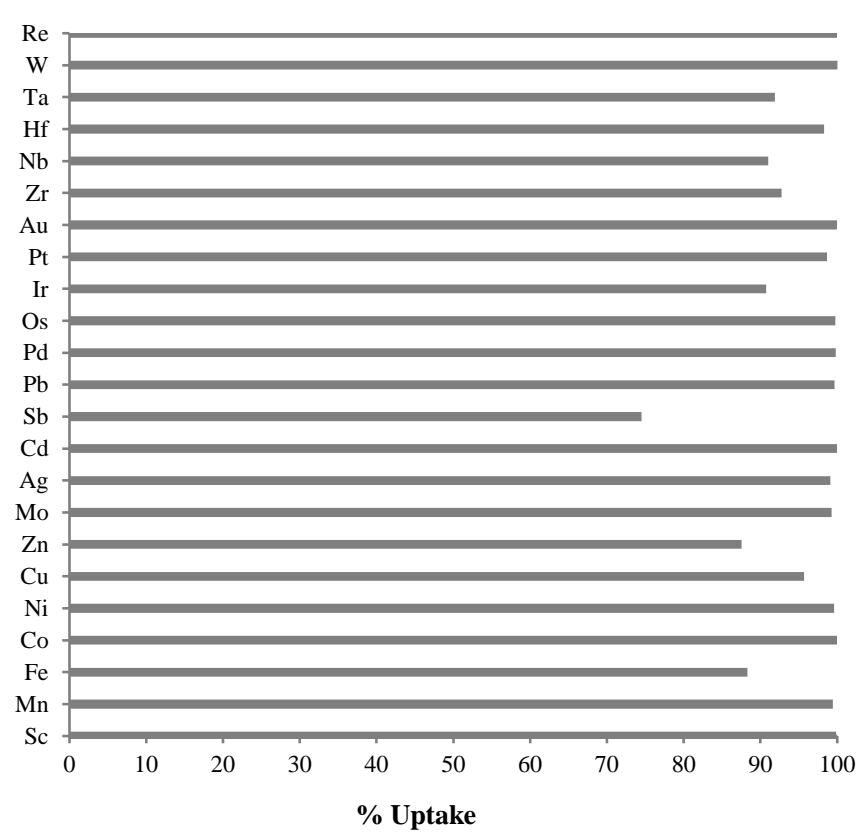

Fig. 4 Percentage uptake of metal ions (100 ppb) from aqueous solution at $\mathrm{pH}$ 0.5 by BTBP-functionalized $\mathrm{SiO}_{2}$ gel 8 .

In summary, we report a promising partitioning process for minor actinides, lanthanides and other fission products based on a column separation technique using novel BTBP/BTPhen immobilized silica gels. The BTBP-functionalized $\mathrm{SiO}_{2}$ gel can be used to remove problematic corrosion and fission products without extracting alkali or alkaline earth metal cations: while the BTPhen-functionalized $\mathrm{SiO}_{2}$ gel extracts both minor actinides and lanthanides at low concentrations of $\mathrm{HNO}_{3}$ yet exhibits very high selectivity for minor actinides over lanthanides at $4 \mathrm{M} \mathrm{HNO}_{3}\left(\mathrm{SF}_{\mathrm{Am} / \mathrm{Eu}}=140\right)$. We propose that this technology could pave the way for the design of an advanced partitioning process for PUREX raffinate consisting of an initial clean-up to remove $d$-block metals and a second stage to remove the minor actinides from the lanthanides. Vitrification and stripping of metals from loaded $\mathrm{SiO}_{2}$ gel will be the subject of further studies in our laboratory.

The authors acknowledge the UK Engineering and Physical Sciences Research Council (grant No. EP/M026485/1) and the Grant
Agency of the Czech Technical University in Prague (grant No. SGS15/216/OHK4/3T/14) for financial support (A.A. and P.D., respectively). Use of the Chemical Analysis Facility (CAF) and Electron Microscopy Laboratory (EMLab) at the University of Reading is gratefully acknowledged. We also would like to thank $\mathrm{Mr}$ Andy Dodson, Dr Peter Harris and Miss Amanpreet Kaur for their assistance with ICP-MS, TEM and SEM measurements, respectively.

\section{References}

1 P. J. Panak and A. Geist, Chem. Rev., 2013, 113, 1199-1236.

2 J.-H. Lan, W.-Q. Shi, L.-Y. Yuan, J. Li, Y.-L. Zhao and Z.-F. Chai, Coord. Chem. Rev., 2012, 256, 1406-1417.

3 M. A. Higginson, N. D. Kyle, O. J. Marsden, P. Thompson, F. R. Livens and S. L. Heath, Dalt. Trans., 2015, 44, 16547-16552.

4 M. P. Jensen, R. Chiarizia, J. S. Ulicki, B. D. Spindler, D. J. Murphy, M. M. Hossain, A. Roca-Sabio, A. de Blas and T. Rodríguez-Blas, Solvent Extr. Ion Exch., 2015, 33, 329-345.

5 L. Xu, A. Zhang, Y. Lu, H. Yang and Z. Liu, RSC Adv., 2016, 6, 99859 99866.

6 C.-L. Xiao, C.-Z. Wang, L. Mei, X.-R. Zhang, N. Wall, Y.-L. Zhao, Z.-F. Chai and W.-Q. Shi, Dalt. Trans., 2015, 44, 14376-14387.

7 Q.-R. Huang, J. R. Kingham and N. Kaltsoyannis, Dalt. Trans., 2015, 44, 2554-2566.

8 J. Veliscek-Carolan, J. Hazard. Mater., 2016, 318, 266-281.

9 M. Houas, N. Amrani and A. Boucenna, Ann. Nucl. Energy, 2016, 97, 198-203.

10 D. M. Whittaker, T. L. Griffiths, M. Helliwell, A. N. Swinburne, L. S. Natrajan, F. W. Lewis, L. M. Harwood, S. A. Parry and C. A. Sharrad, Inorg. Chem., 2013, 52, 3429-3444.

11 N. T. Coogan, M. A. Chimes, J. Raftery, P. Mocilac and M. A. Denecke, J. Org. Chem., 2015, 80, 8684-8693.

12 C. Wagner, U. Mullich, A. Geist and P. J. Panak, Dalt. Trans., 2015, 44, 17143-17151.

13 A. Bremer, D. M. Whittaker, C. A. Sharrad, A. Geist and P. J. Panak, Dalt. Trans., 2014, 43, 2684-2694.

14 B. B. Beele, A. Skerencak-Frech, A. Stein, M. Trumm, A. Wilden, S Lange, G. Modolo, U. Mullich, B. Schimmelpfennig, A. Geist and P. J. Panak, New J. Chem., 2016, 40, 10389-10397.

15 A. C. Edwards, C. Wagner, A. Geist, N. A. Burton, C. A. Sharrad, R. W. Adams, R. G. Pritchard, P. J. Panak, R. C. Whitehead and L. M. Harwood, Dalt. Trans., 2016, 45, 18102-18112.

16 D. Magnusson, B. Christiansen, M. R. S. Foreman, A. Geist, J. -P. Glatz, R. Malmbeck, G. Modolo, D. Serrano-Purroy and C. Sorel, Solvent Extr. Ion Exch., 2009, 27, 97-106.

17 F. W. Lewis, L. M. Harwood, M. J. Hudson, U. Mullich and A. Geist, Chem. Commun., 2015, 51, 9189-9192.

18 T. Kikuchi, M. Nogami and K. Suzuki, J. Alloys Compd., 2004, 374, 272 276.

19 M. Kaur, H. Zhang, L. Martin, T. Todd and Y. Qiang, Environ. Sci. Technol., 2013, 47, 11942-11959.

20 J. A. Shusterman, H. E. Mason, J. Bowers, A. Bruchet, E. C. Uribe, A. B. Kersting and H. Nitsche, ACS Appl. Mater. Interfaces, 2015, 7, $20591-$ 20599.

21 M. A. Higginson, O. J. Marsden, P. Thompson, F. R. Livens and S. L. Heath, React. Funct. Polym., 2015, 91-92, 93-99.

22 A. Afsar, L. M. Harwood, M. J. Hudson, M. E. Hodson and E. J. Shaw, Chem. Commun., 2014, 50, 7477-7480.

23 A. Afsar, L. M. Harwood, M. J. Hudson, P. Distler and J. John, Chem. Commun., 2014, 50, 15082-15085.

24 F. W. Lewis, L. M. Harwood, M. J. Hudson, P. Distler, J. John, K Stamberg, A. Núñez, H. Galán and A. G. Espartero, European J. Org. Chem., 2012, 2012, 1509-1519.

25 F. W. Lewis, L. M. Harwood, M. J. Hudson, A. Geist, V. N. Kozhevnikov, P. Distler and J. John, Chem. Sci., 2015, 6, 4812-4821.

26 S. Tai, N. J. Williams and J. D. Carrick, J. Heterocycl. Chem., 2016, 53 307-312.

27 F. W. Lewis, L. M. Harwood, M. J. Hudson, M. G. B. Drew, A. Wilden, M. Sypula, G. Modolo, T.-H. Vu, J.-P. Simonin, G. Vidick, N. Bouslimani and J. F. Desreux, Procedia Chem., 2012, 7, 231-238.

28 D. M. Laventine, A. Afsar, M. J. Hudson and L. M. Harwood, Heterocycles, 2012, 86, 1419-1429.

29 M. J. Hudson and Z. Matejka, Sep. Sci. Technol., 1989, 24, 1417-1426. 